\title{
MODELLING THE EFFECTS OF FAILURE OF PIPELINES TRANSPORTING HYDROGEN
}

\author{
Andrzej Rusin*, Katarzyna Stolecka \\ Silesian University of Technology, Institute of Power Engineering and Turbomachinery, \\ ul. Konarskiego 18, 44-100 Gliwice
}

\begin{abstract}
The depletion of stocks of fossil fuels and the environment protection requirements increase the significance of hydrogen as a future energy carrier. The present research is focused on the development of new safe methods of production, transport and storage of hydrogen. The paper presents an analysis of problems related to the assessment of the effects of failure of hydrogen transporting pipelines. Scenarios of hazardous events connected with an uncontrollable leakage of hydrogen are discussed. The sizes of heat radiation and pressure wave hazard zones are determined.
\end{abstract}

Keywords: hydrogen pipelines, jet fire, explosion

\section{INTRODUCTION}

The dynamic situation on the energy market related to the depletion of stocks of fossil fuels and to the environment protection requirements increases the significance of hydrogen as a future energy carrier. Intensive work is now being done in many research centres to develop new methods of hydrogen production, transport and storage (Elvers, 2008; Gerboni and Salvador, 2009; Rigas and Sklavounos, 2005; Surygała, 2008; Yo and Ahn, 2006). The determination of safety conditions becomes an essential problem at each stage of using hydrogen as a fuel or a raw material in chemical processes. This results from the fact that hydrogen belongs to relatively hazardous substances. Its uncontrollable release from any component of hydrogen facilities in the processes of production, transport or storage presents hazard both to the staff operating the facilities, as well as to the immediate surroundings. One of the documents that regulates these issues is EC Regulation (2009). The results of the analysis of hazard zones presented below relate to the areas around hydrogen transporting pipelines whose break initiated an uncontrollable gas leakage. Potential scenarios of events caused by a leakage of hydrogen are discussed. Calculation models are presented to assess the level of heat radiation at the fire of hydrogen which flows out, as well as the size of overpressure resulting from an explosion of a cloud of released gas. The undesirable effects on human life and on the environment were calculated depending on the distance from the pipeline break.

\section{PHYSICAL AND CHEMICAL PROPERTIES OF HYDROGEN}

Under normal conditions hydrogen is a gas of a very low density of $0.08374 \mathrm{~kg} / \mathrm{m}^{3}$. With increasing pressure the density of hydrogen rises, but not as fast as it could be expected from the equation of the state of ideal gas. Its density in the liquid state is $70.8 \mathrm{~kg} / \mathrm{m}^{3}$, and in the crystalline state $-88 \mathrm{~kg} / \mathrm{m}^{3}$.

*Corresponding author, e-mail: andrzej.rusin@polsl.pl 
The product of hydrogen burning is water and considerable amounts of released energy. The high heat value and lower heating value of hydrogen are: $141.86 \mathrm{MJ} / \mathrm{kg}$ and $119.93 \mathrm{MJ} / \mathrm{kg}$, respectively. These values are much higher than those of other gas fuels such as methane or propane. In comparison with other fuels the so-called energy density of hydrogen is relatively low, which causes the need for a construction of high-volume tanks for hydrogen transport and storage. Some other properties of hydrogen, such as the ignition temperature of $-253^{\circ} \mathrm{C}$ and the self-ignition temperature of $585^{\circ} \mathrm{C}$ are also essential from the point of view of its practical applications. The latter temperature is higher than that for petrol, methanol, propane or methane. A characteristic feature of hydrogen which has a great impact on the safety of its use is the wide range of its flammability in air - from 4 to $75 \mathrm{vol} \%$, whereas for methane, for example, the range is only $5.3-15 \mathrm{vol} \%$. Another property which has an impact on the potential hazard of hydrogen catching fire is its low ignition temperature, i.e. the minimum amount of outer energy, which, when supplied to hydrogen, can cause its ignition. The value for a stoichiometric mixture of hydrogen is only $0.02 \mathrm{~mJ}$, whereas for other fuels the energies are more than ten times higher. Such a low value of the hydrogen ignition energy leads to a situation where any uncontrollable leakage might end in a fire, and the igniting spark can result from the friction of the hydrogen mass outflow itself, or from the electrostatic influence of objects such as clothes.

Another important value characterising the burning process of hydrogen is the burning rate, i.e. the rate at which the flame spreads through the combustible mixture of hydrogen. It is much higher than for other fuels and ranges from 2.65 to $3.25 \mathrm{~m} / \mathrm{s}$. The flame of burning hydrogen is almost invisible and the phenomenon of soot formation does not occur in it. Heat is emitted in a narrow band of infrared, primarily from steam. Adiabatic flame temperature of burning hydrogen exceeds $2300 \mathrm{~K}$.

\section{HYDROGEN PRODUCTION, TRANSPORT AND STORAGE}

The production of hydrogen for chemical and, recently, for power purposes has been growing steadily (Elvers, 2008; Surygała, 2008). Its sources are first of all natural gas, crude oil and coal, but also water. The basic technologies used to obtain hydrogen are: water electrolysis, coal gasification, steam reforming of methane, etc. Apart from those classical hydrogen production methods, new technologies appear, such as: the thermo-chemical dissociation of hydrocarbons, the thermo-chemical decomposition of hydrogen sulphide and water, biomass gasification, or biological methods (Elvers, 2008; Surygała, 2008). The oldest and the best known way to obtain hydrogen is water electrolysis.

Another production technology is steam reforming of methane. This is the most common method of hydrogen production in industry. The action of steam on methane in the presence of catalysts results in the creation of a synthesis gas composed of $75 \%$ of $\mathrm{H}_{2}$, and also of $\mathrm{CO}$ and $\mathrm{CO}_{2}$. The further stages of the process are: the conversion of $\mathrm{CO}$ in the presence of $\mathrm{H}_{2} \mathrm{O}$ to $\mathrm{CO}_{2}$ and $\mathrm{H}_{2}$, and the removal of $\mathrm{CO}_{2}$.

Coal gasification is a technology that consists in the action of steam on coke, which leads to a formation of gas composed of $\mathrm{CO}$ and $\mathrm{H}_{2}$. The gas is subject to a further action of water in the presence of catalysts, which finally gives $\mathrm{CO}_{2}$ and $\mathrm{H}_{2}$. Biological methods which make use of sunlight, water and biomass may be the way of hydrogen production in the future. These are photobiological processes which make use of algae, for example. Another promising method of hydrogen production is biomass gasification. It is based on the process of a thermo-chemical transformation or anaerobic fermentation. The problem related to biomass gasification is the release of substances such as tar or gaseous hydrocarbons which occurs in the process. Fermentation is a hydrogen production method which makes use of biomass decomposition by anaerobic bacteria. This method, however, is not very effective.

The selection of hydrogen production method has an impact on the ways and costs of its distribution. The most advantageous option would be to use hydrogen at the site of its manufacture. As this is not 
always possible, hydrogen has to be stored. Also, in this field a continuous progress is made and new technologies are developed (Buczek et al., 2007).

Pressure tanks are the most popular means of hydrogen storage. Their shape is usually cylindrical and the gas is stored in them under the pressure of 35 or $70 \mathrm{MPa}$. The compression process itself is a multistage one, and it requires substantial amounts of energy. Moreover, the tanks in use are large and heavy. As well as this, a hydrogen molecule is leakage-prone due to its small size. The impact of hydrogen on construction materials, including steels, should also be borne in mind. Under some conditions and with a proper length of time of hydrogen contact with steel, hydrogen embrittlement can take place.

Liquid hydrogen occupies less space than compressed hydrogen. A tank of the same capacity with liquid hydrogen can hold more hydrogen than a tank with compressed hydrogen. Liquid hydrogen is obtained by cooling it to a temperature below $20 \mathrm{~K}$. It is a rather energy-consuming process but it allows hydrogen transport in insulated tanks with thinner walls (due to a lower pressure inside). Consequently, the pressure tanks are much lighter. Such tanks, however, have to be well insulated thermally to prevent partial hydrogen evaporation caused by heat penetrating through tank walls. A vehicle carrying liquid hydrogen takes a larger mass of hydrogen than its mass contained in cylinders in the gas state, which makes transport more economical.

Metal hydrides are hydrogen-absorbing materials. They are usually alloys with a sponge-like structure which allows hydrogen absorption or its reactions with various metal alloys in order to store it. Typically, they are alloys of nickel, magnesium or iron. Filling occurs by increasing pressure and cooling the tank. Emptying is caused by decreasing pressure and heating the tank. This is the safest method of hydrogen storage, but tanks with hydrides are heavy due to the mass of metals.

Carbon nanotubes are a new hydrogen storage technology developed in recent years. They are tube-like structures in which hydrogen can be stored either in the tubes or in the space between them. The existing systems feature a good absorption efficiency. It seems, therefore, that large amounts of hydrogen can be stored with a small mass.

Large amounts of hydrogen can be transported by pipelines, rail or road transport (Gerboni and Salvador, 2009). Except for the United States, most countries do not have an appropriate pipeline network at the moment. However, it can be expected that such networks will be constructed in the near future. Hydrogen can also be transported by the existing natural gas pipelines with some modifications.

Rail transport can play an important part in the transition period as an alternative to the insufficient pipeline network. Carrying hydrogen in rail tanks or by road allows its transport in both the gas and liquid states. To transport compressed hydrogen, tanks in which the gas is under the pressure of 21, 35 or $70 \mathrm{MPa}$ are used. The higher the pressure of the transported hydrogen, the lower the costs of its delivery at long distances.

\section{SCENARIOS AND EFFECTS OF EVENTS CAUSED BY PIPELINE BREAKS}

A detailed analysis of hydrogen-related accidents indicates that their most common cause is a rupture of components of facilities, pipelines or tanks, as well as undetected leakages, especially of fittings. In the following part, a scenario and effects of a break of a pipeline transporting hydrogen are considered. This is the most serious possible failure of any hydrogen infrastructure whose results can affect vast areas (Yo and Ahn, 2006).

A break of a pipeline with hydrogen which results in an uncontrollable leakage of gas can create a potential fire or explosion hazard (Fig. 1). 


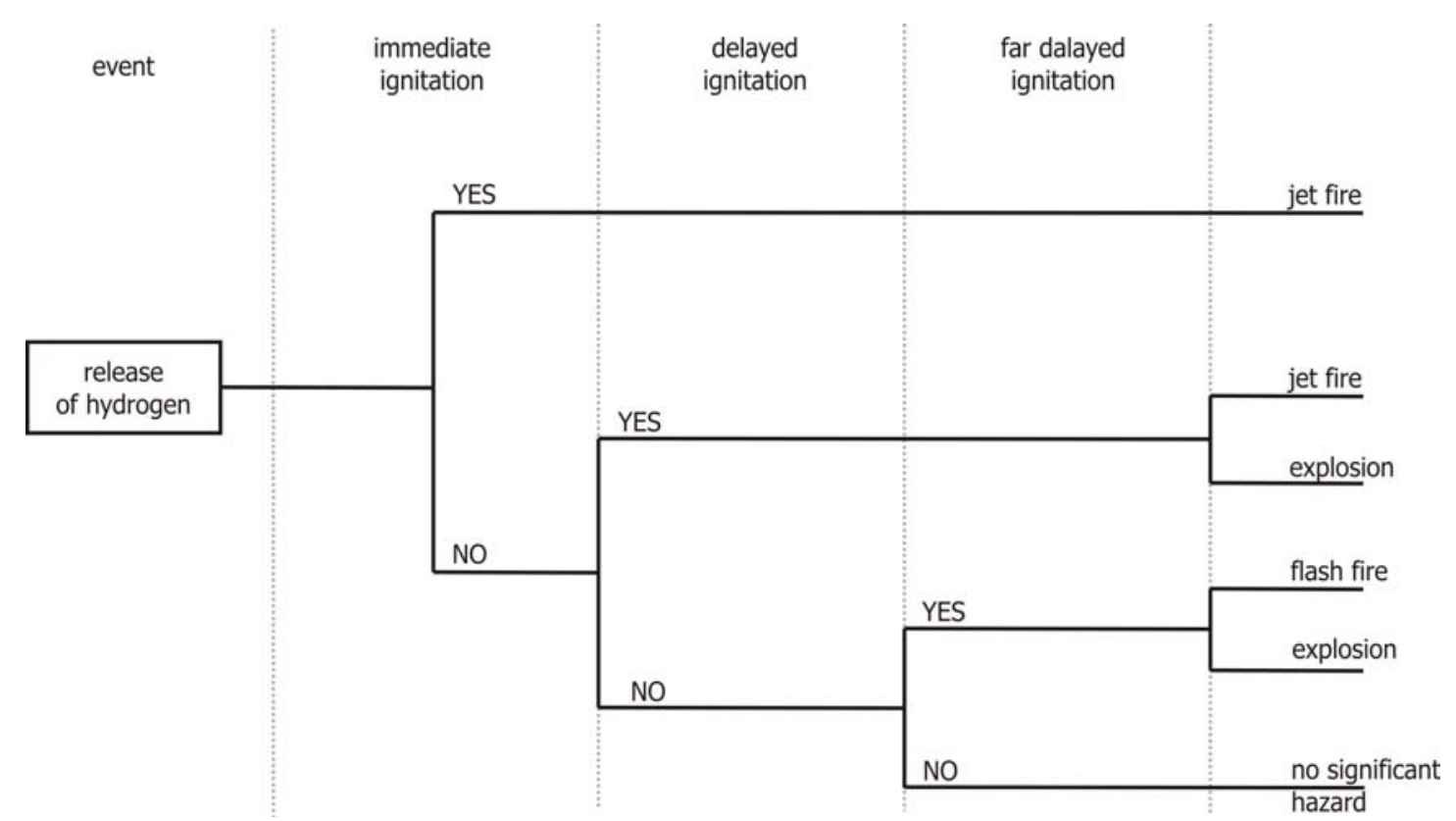

Fig. 1. A pipeline failure event tree

The most common type of fire resulting from the release of hydrogen is the jet fire, whose effect is strong heat radiation emitted by a long, steady flame (Houf and Schefer, 2007; Mogi and Horiguchi, 2009; van den Bosch and Weterings, 2005). In turbulent mixing of released hydrogen with air, there is also a hazard of explosion, which results in a pressure wave. Which of these hazards will occur in a particular case depends on the moment of the released gas ignition. At immediate ignition the result is a jet fire. At a delayed ignition - a cloud of hydrogen may form, and then explode. If there is no ignition, the released hydrogen may disperse in the atmosphere with no adverse effect.

While analysing accident scenarios, it is important to assess the consequences for humans and the surroundings. For this purpose a function is used, which combines the magnitude of the impact - e.g. fire heat radiation - with a the range of damage caused by the accident. This is often referred to as the probit function with the following general form (Lachance et al. 2011):

$$
P_{r}=a+b \ln V
$$

where: $P_{r}$ is the percentage of the population exposed to a given injury caused by load $V$. The constant values $\mathrm{a}$ and $\mathrm{b}$ are determined empirically.

During a fire, the main hazard to humans and surroundings is heat radiation which depends on the type of fire and the type of the released substance. Obviously, the percentage of humans exposed to a given effect caused by thermal load depends also on the time of exposure to heat radiation and the distance from the centre of the fire. If the assumed effect of fire is death from burns, the probit function has the form (Lachance et al. 2011):

$$
P_{r}=-14,9+2,56 \ln \left(\frac{t q^{4 / 3}}{10^{4}}\right)
$$

where:

$q$ - radiational heat flux, $\mathrm{W} / \mathrm{m}^{2}$

$t$ - time of exposure, $\mathrm{s}$

$P_{r}-$ probit function 
The effect of an explosion is a pressure wave, but also fragments of a torn tank for example, which may act as missiles. The wounds and injuries to the human body, as well as deaths, depend on the location of a human in relation to buildings, and the position of the body. In the case of an explosion, the basic probit function related to fatal injuries to a human has the function:

$$
P_{r}=-77,1+6,91 \ln (\Delta p)
$$

where: $\Delta p$ is the overpressure caused by explosion.

The calculated values of probit functions can be converted into percentages of the population exposed to the effect of a given event. For example, the probit function value of 7.33 corresponds to $99 \%$ of deaths in the population, and the value of $2.67-$ to $1 \%$.

\section{MODELS OF HYDROGEN LEAKAGE EFFECTS}

\subsection{Flame radiation of burning hydrogen}

One of the possible effects of an uncontrolled release of gas from a damaged system is a fire hazard. One of the most dangerous of all kinds of fires is what is referred to as the jet fire. Its effect is an extremely strong heat radiation emitted by the flame. An estimation of the radiation value is still a crucial research subject, and the proposed models, such as source models, multi-point models and surface source models are approximate semi-empirical models.

In practice, the third model is the one which is used most often, with an assumption that a part of the combustion heat radiates through the visible surface of the flame. The theoretical surface energy of heat radiation in a unit of time can be calculated from the dependence:

$$
E_{t}=\frac{Q_{s}}{A}
$$

where:

$Q_{s}$ - combustion energy per time unit, $\mathrm{J} / \mathrm{s}$

$A$ - flame surface area, $\mathrm{m}^{2}$

Value $Q_{s}$ can be calculated knowing the mass flow rate of the burning gas and combustion heat $H_{c}$. Only part of this energy will be transferred through radiation, therefore:

$$
E=\eta E_{t}
$$

where: $\eta$ describes the share of radiated energy in total combustion energy.

The value depends on the kind of fire and also on the kind of burning substance. A unit heat flux received by a surface at a certain distance from the flame can be calculated from the dependence:

$$
q=E F \tau_{a}
$$

where: $F$ is the view factor dependent on the distance and the location of the surface receiving the radiation in relation to the radiating flame area, and on the flame shape. Value $\tau_{a}$ describes air transmissivity between the receiver and the emitter, which is dependent mainly on steam and carbon dioxide content in the air.

Other important features of the flame of the burning gas are its dimensions, i.e. its length $L_{f}$ and its width $W_{f}$. 
The reference literature presents various models which take into account more details for Relation (6). The simplest of them, which defines a unit heat flux at distance $r$ from the flame centre, is described by (Guidelines, 1998; Yo and Ahn, 2006):

$$
q=\frac{\eta \tau_{m} \dot{m}_{e} H_{C}}{4 \pi r^{2}}
$$

In Eq. (7) $\dot{m}_{e}$ denotes what is referred to as the effective gas flow smaller than the theoretical maximum flow $\dot{m}_{\max }$ described for the case of the critical outflow by the formula:

$$
\begin{gathered}
\dot{m}_{\max }=A_{o} \sqrt{\rho_{k} p_{k} \kappa\left(\frac{2}{\kappa+1}\right)^{\frac{\kappa+1}{\kappa-1}}} \\
\dot{m}_{e}=c m_{\max }
\end{gathered}
$$

Coefficient $c$ usually assumes a value within the range of 0.3 to 1 .

Experimental studies of the hydrogen flame presented in (Mogi and Horiguchi, 2009) made it possible to work out the following empirical dependencies for calculating a unit heat flux at distance $r$ from the flame:

$$
q=\frac{a_{s} \dot{m}^{b_{s}}}{r^{2}}
$$

where: $a_{s}, b_{s}$ - constants established empirically, equalling $6 \cdot 10^{5}$ and 1.3 , respectively. In the above dependence, the gas flow should be expressed in $\mathrm{kg} / \mathrm{s}$; consequently, heat flux $q$ will be expressed in $\mathrm{W} / \mathrm{m}^{2}$.

This research was the basis to establish the relationships between gas flow and a flame length $L_{f}$.

$$
L_{f}=a_{l} m^{b_{l}}
$$

where: $a_{l}$ and $b_{l}$ are constants.

A more elaborate model, also based on experimental studies of hydrogen flame, was presented in (Houf and Schefer, 2007; Scheffef et al., 2007). In that model, a non-dimensional value $c^{*}$ was defined, which describes the relative radiation size along the flame length.

$$
c^{*}=f\left(\frac{x}{L_{f}}\right)
$$

It was found out that the maximum value $c^{*}$ of approx. 0.85 occurred for $x / L_{f}$ contained in the range of 0.6 to 0.7 (Houf and Schefer, 2007; Scheffef et al., 2007). The value of radiation heat flux is described by the dependence:

$$
q=c^{*} \frac{S_{r a d}}{4 \pi r^{2}}
$$

where:

$$
S_{r a d}=\dot{m} H_{c} X_{r}
$$

Value $X_{r}$ corresponding to the ratio of radiated energy to total chemical energy of the burning gas was in turn made dependent, according to research findings, on value $\tau_{f}$, which has a time dimension and which is defined as follows (Houf and Schefer, 2007; Scheffef et al., 2007): 


$$
\tau_{f}=\frac{\rho_{f} W_{f}^{2} L_{f} f_{s}}{3 \rho_{o} d_{i}^{2} u_{i}}
$$

where: $\rho_{f}, W_{f}, f_{s}$ are the density, width and length of the flame. $f_{s}$ corresponds to the ratio of the masses in the stoichiometric mixture of hydrogen and air, $d_{i}$ is the diameter of the gas outflow hole, $u_{i}$ - the rate of the outflow, and $\rho_{o}$ the density of the gas flowing out. After time $\tau_{f}$ is established from Equation (15), $X_{r}$ is calculated, and then, with the use of formulae (13) and (14) - the unit heat flux in function of distance $r$.

\subsection{Models of explosion effects}

The gas released during the failure of a hydrogen system mixes with air and may form a flammable cloud. If the cloud comes into contact with an ignition source, it may catch fire and an explosion may occur. The hazard related to such explosion is proportional to its magnitude. There are two main methods to determine explosion effects. One assumes that the explosion energy is proportional to the total amount of gas contained in the cloud. This is referred to as the TNT equivalent method (Gerboni and Salvador, 2009; Guidelines, 1998; Lobato et al., 2006). The other, called the multi-energy method, assumes that the explosion sources are turbulences in a cloud which finally result in an explosion (Gerboni and Salvador, 2009; Lobato et al., 2006). These turbulences can be caused both by an outflow of gas from a damaged system and by infrastructure and landform features in the area of the created cloud. A gas explosion can be treated as a series of explosions, each corresponding to individual turbulence sources. More details of both models are discussed below.

The TNT model is one of the simplest models with universal application. It allows to calculate overpressure at any distance from the site of explosion of a hazardous substance. The model is based mainly on observations of real explosions and on experience related to them. The main idea of the model is the conversion of the released mass of the substance causing explosion into an equivalent mass of TNT, according to Equation (Guidelines, 1998; Lobato et al., 2006):

$$
W_{T N T}=\frac{m_{g} \alpha H_{C}}{H_{C T N T}}
$$

where:

$W_{T N T}$ - the mass of equivalent TNT in terms of explosion effects of a given substance,

$\alpha$ - a non-dimensional coefficient which determines the content of the exploding gas in the cloud, and

its value is included in the range of $1 \div 10 \%$,

$m_{g}$ - the total hydrogen mass in the cloud,

$H_{C}$ - the lower heat of combustion,

$H_{C T N T}$ - the heat of combustion of TNT.

The equivalent value of mass $W_{T N T}$ calculated above is then converted into a standardised distance $z$ in the following way:

$$
z=\frac{r}{\left(W_{T N T}\right)^{1 / 3}}
$$

where: $r$ is the real distance expressed in units of length $(\mathrm{m})$. Each standardised distance $z$ corresponds to an overpressure value $\Delta p$, read from graphs developed on the basis of empirical studies (Guidelines, 1998; Lobato et al., 2006).

In the multi-energy model the explosion magnitude is determined for each part of the cloud burning in conditions of intense turbulence. The turbulence can be caused by the jet of gas flowing out of a 
damaged tank or pipeline. Its sources can also be limitations and barriers in the surroundings of the forming gas cloud, such as walls of buildings. Over each such source of turbulence which may be a potential centre of an explosion, the amount of the gas-air mixture has to be determined, and then its combustion energy $E$ has to be calculated. The energy will next be used to calculate what is referred to as scaled distance $\bar{R}$ from the explosion centre, according to the following dependence:

$$
\bar{R}=\frac{r}{\left(\left(\frac{E}{p_{0}}\right)^{1 / 3}\right)}
$$

where: $r$ is the real distance from the explosion centre, and $p_{o}$ is the ambient pressure. The value will then be used to calculate non-dimensional overpressure $\Delta \bar{p}$ caused by a given sub-explosion in its surroundings. For this purpose, empirical dependencies $\Delta \bar{p}=f(\bar{R})$ are used, which were developed on the basis of observations and studies of real explosions (Guidelines, 1998). Graphic forms of such explosions were developed for different values of the explosion initial magnitude which were divided into 10 categories, starting from the smallest explosion which could occur in an open, unlimited space, to the biggest one corresponding to an explosion in an entirely limited space. The real overpressure that results from a given explosion is calculated from the dependence:

$$
\Delta p=\Delta \bar{p} p_{o}
$$

With relatively close distances between sources of potential turbulences, all explosions may coincide. In this case, for a preliminary and safe assessment of their effects, the energy of the gas contained in the cloud in Equation (18) can be assumed as total, and the value $\Delta \bar{p}$ can be determined on the basis of the curves developed for explosions of the greatest magnitude.

\section{ASSESSMENT OF THE FAILURE EFFECTS}

Hydrogen properties and the hazards resulting from its uncontrollable release from transport pipelines which were discussed earlier indicate that the most dangerous effects can be jet fires and explosions of the hydrogen cloud. The results of calculations of a range of effects of such events are presented below. The first stage of such analyses is the determination of the amount of hydrogen. The amount depends on the hydrogen pressure in the pipeline and the size of the outflow hole. Two diameter variants of the outflow hole were adopted for the calculations: $0.05 \mathrm{~m}$ and $0.4 \mathrm{~m}$. The first variant corresponds to a relatively small damage to the pipeline. The other value relates to a complete break of the pipeline. Assuming the critical outflow, the outflow rate can be determined from Dependence (8).

The size of the outflow, along with its parameters, can be calculated by means of numerical calculations, e.g. with the Ansys CFX v.11 software package. Some examples of calculations of the maximum mass outflow of gas in function of the pressure in the pipeline for different hole diameters are given in Fig. 2. The distribution of hydrogen velocity in the immediate vicinity of the outflow hole is given in Fig. 3. The following data were adopted for the calculation of the mass outflow, heat radiation and overpressure values: $H_{C}=141.9 \mathrm{MJ} / \mathrm{kg}, \kappa=1.41, \eta=0.15, \alpha=0.1$, $H_{C T N T}=4200 \mathrm{~kJ} / \mathrm{kg}$.

The value of heat radiation caused by a jet fire in function of distance and pipeline pressure was calculated with the algorithms presented in Section 4. Point source model (Eq.7) was used to estimate the size of radiation. The calculation results for different hydrogen outflow diameters are given in Figures 4 and 5. Three characteristic radiation levels corresponding to wood ignition (level 1), plastic strain of steel structures (level 2) and a major damage to infrastructure components (level 3) were marked in the figures. 


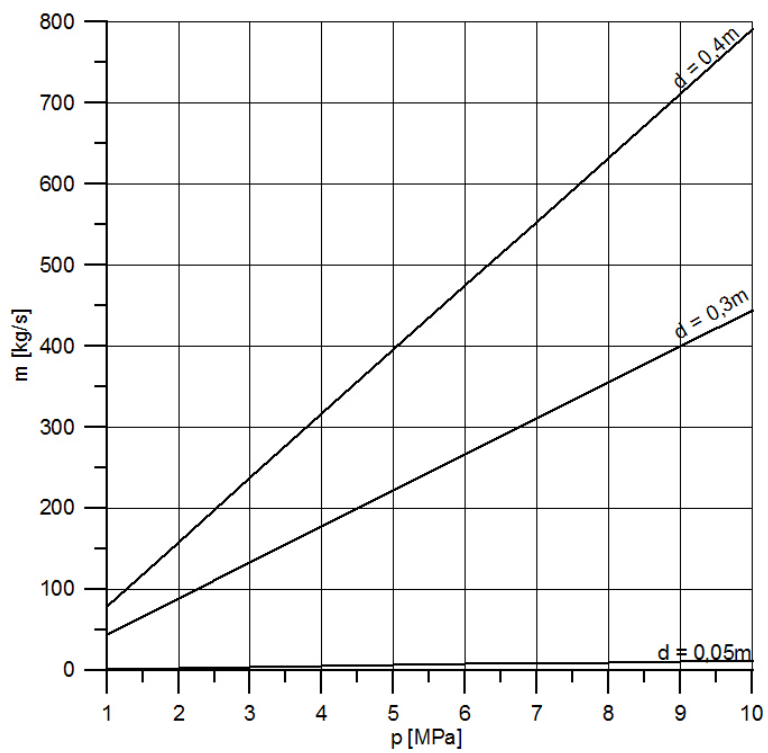

Fig. 2. Dependence of the maximum hydrogen outflow on the pipeline pressure

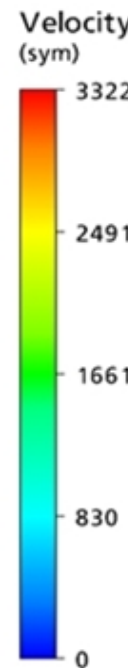

[m $\left.s^{\wedge}-1\right]$

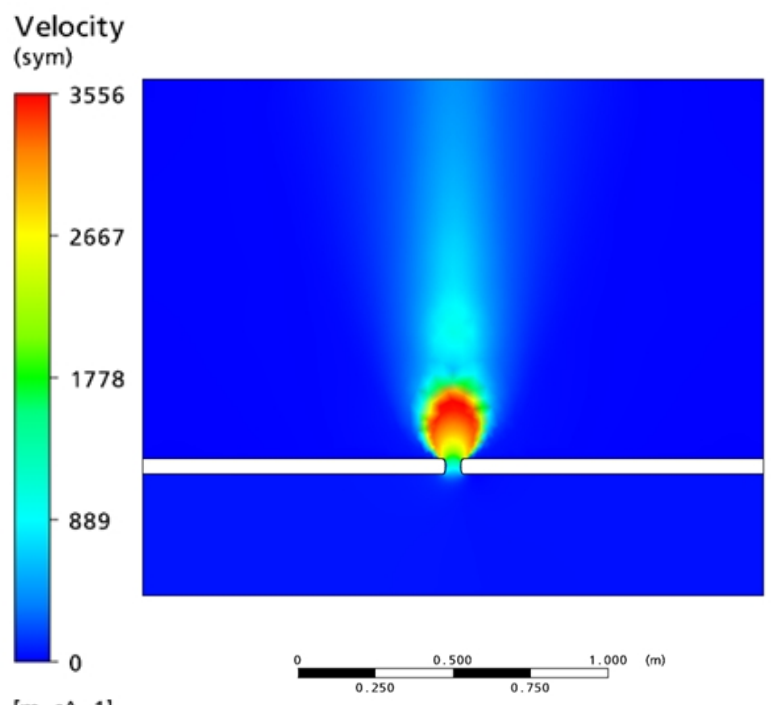

[m $\mathrm{s}^{\wedge}-1$ ]

Fig. 3. Hydrogen velocity value at the outflow from the broken pipeline

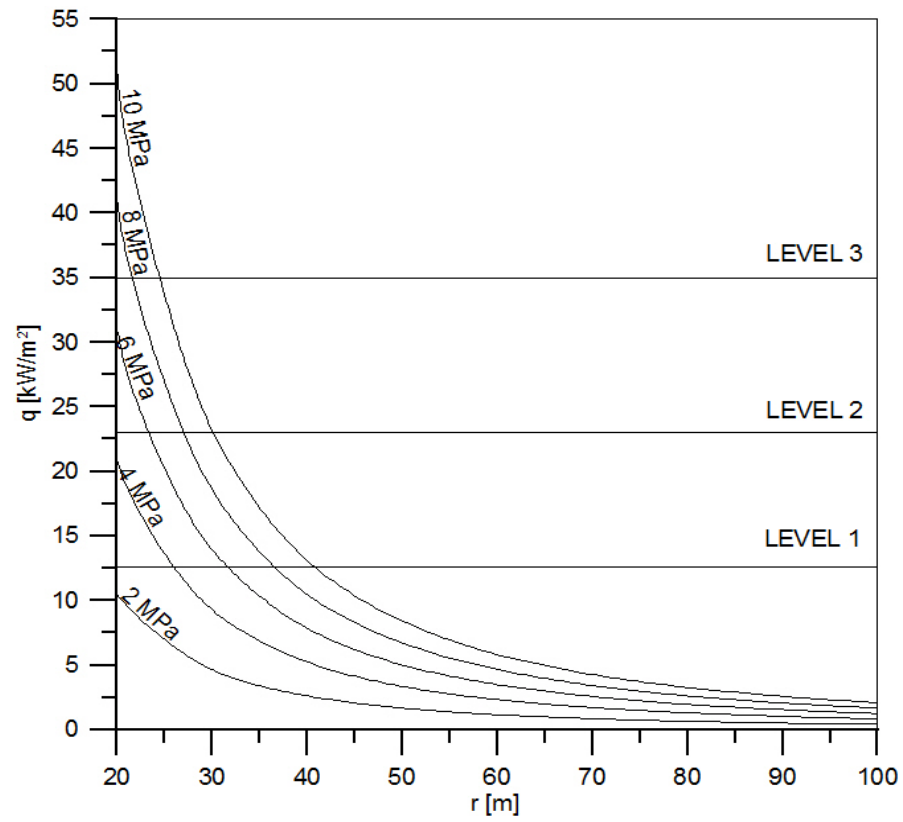

Fig. 4. Dependence of the heat flux on distance from the fire source $(d=0.05 \mathrm{~m})$ 


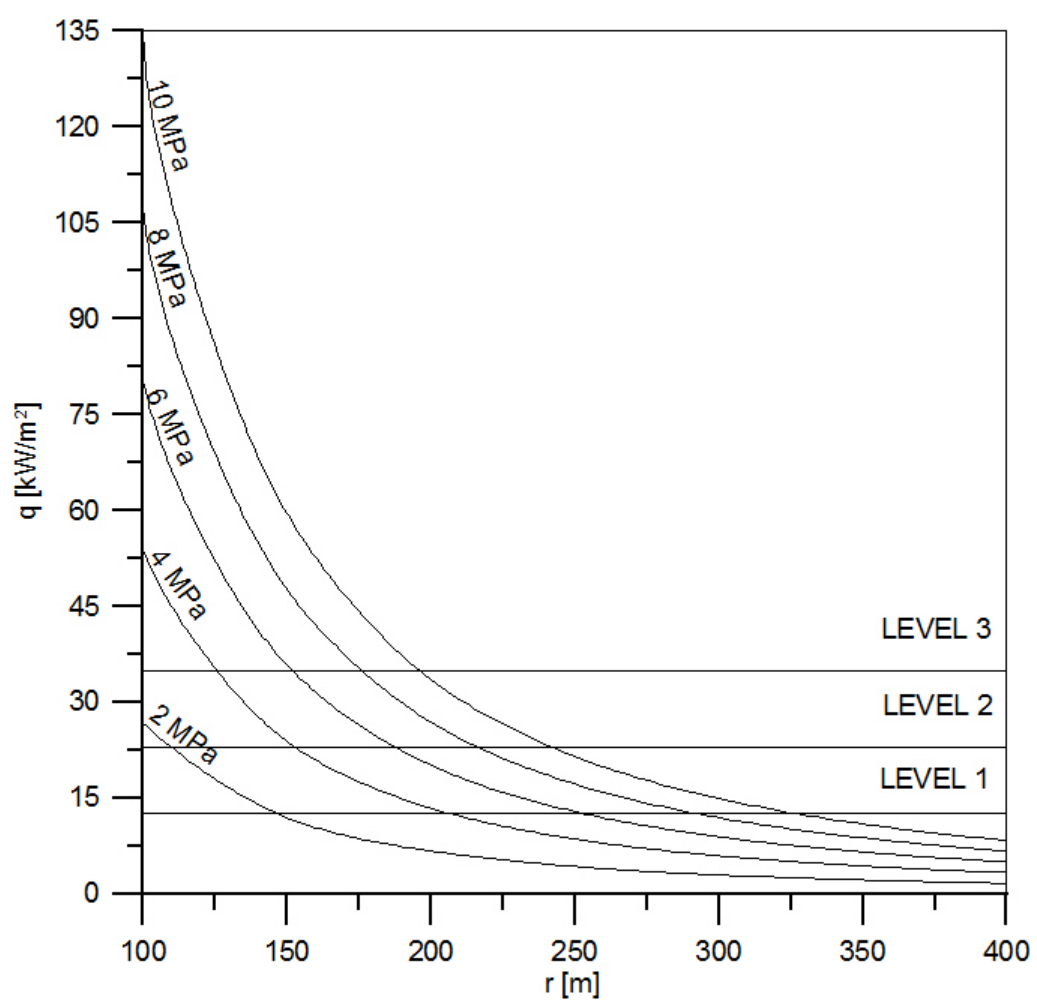

Fig. 5. Dependence of the heat flux on distance from the fire source $(d=0.4 \mathrm{~m})$

The following Figures $6 \div 9$ present a range of critical zones at a jet fire in function of the pressure in the pipeline. The individual curves in the figures correspond to the fatal burn probability of $1 \%, 50 \%$ and $99 \%$, respectively. Figures 6 and 7 show this dependence for two different gas outflow diameters and a 15 -second exposure to radiation. Figures 8 and 9 relate to a longer exposure time of $30 \mathrm{~s}$.

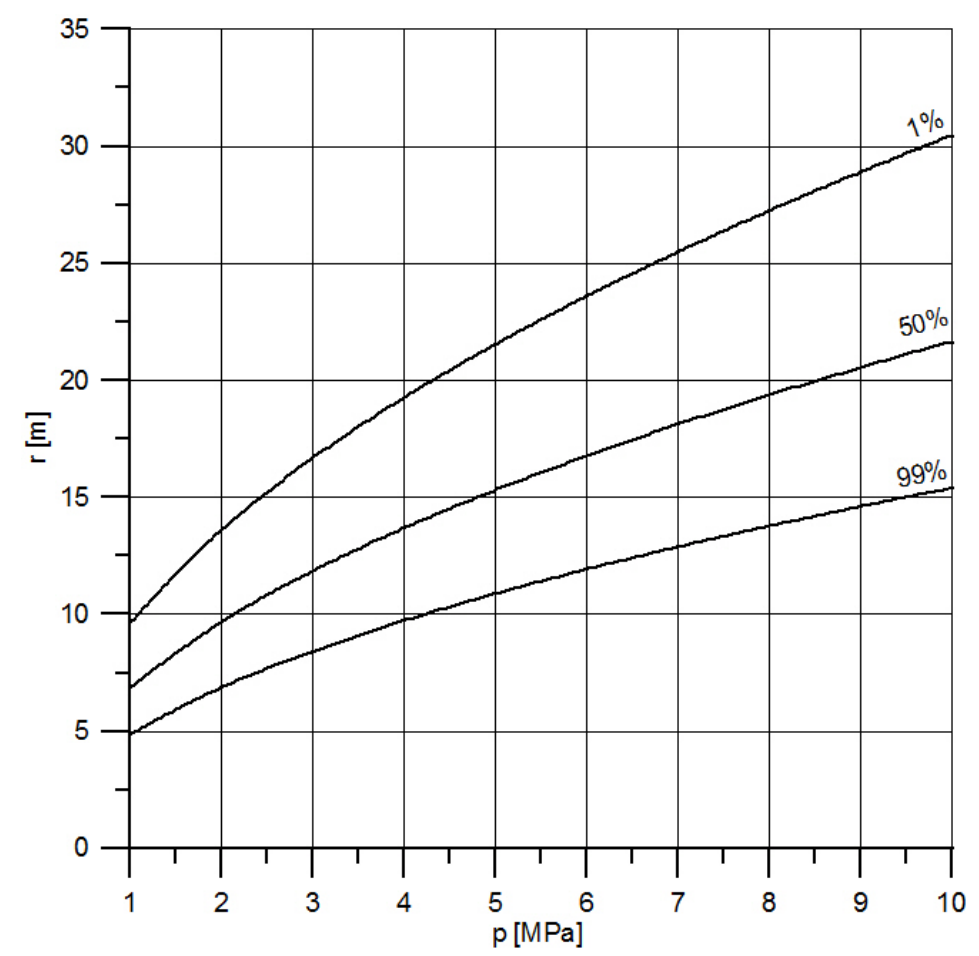

Fig. 6. Dependence of the size of hazardous zones on the gas pressure $(d=0.05 \mathrm{~m})$ 


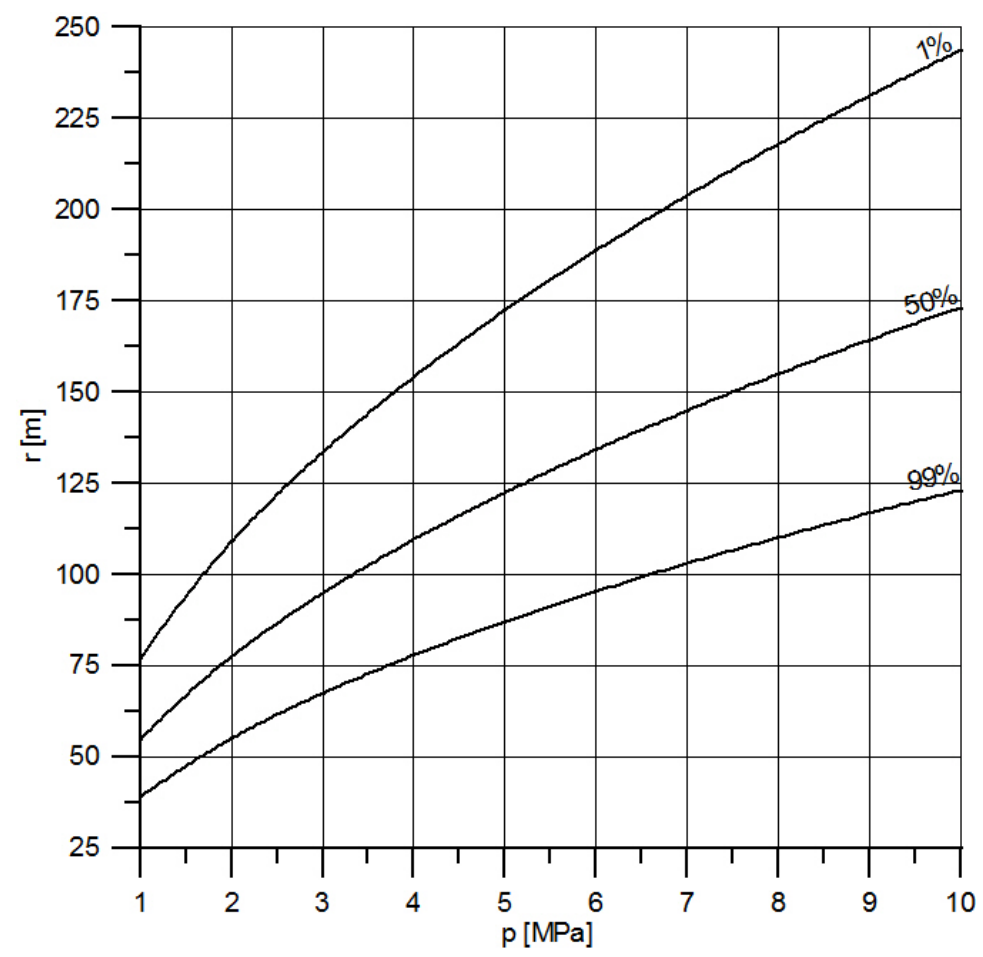

Fig. 7. Dependence of the size of hazardous zones on the gas pressure $(d=0.4 \mathrm{~m}, t=15 \mathrm{~s})$

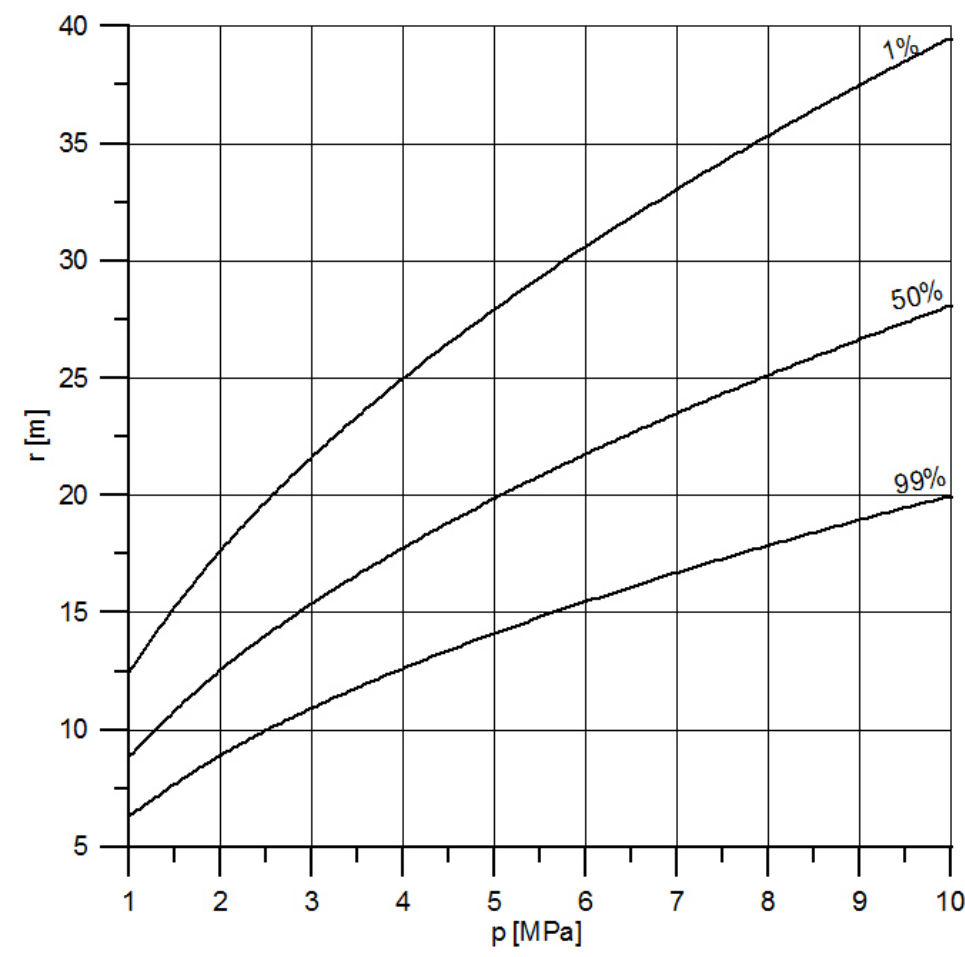

Fig. 8. Dependence of the size of hazardous zones on the gas pressure $(d=0.05 \mathrm{~m}, t=30 \mathrm{~s})$

Another possible negative effect of an uncontrollable leakage of hydrogen from a broken pipeline is the explosion of the cloud of the released gas. Some examples of values of the resulting overpressure in function of distance were given in Figures $10 \div 13$. The curves presented in the figures relate to the cloud explosion which occurred 10s after the release of hydrogen from the pipeline (Fig. 10,12) and after $60 \mathrm{~s}$ after the cloud started to form. The characteristic levels of overpressure causing phenomena such as window breaking, wall cracking or building destruction were also marked in the figures. 


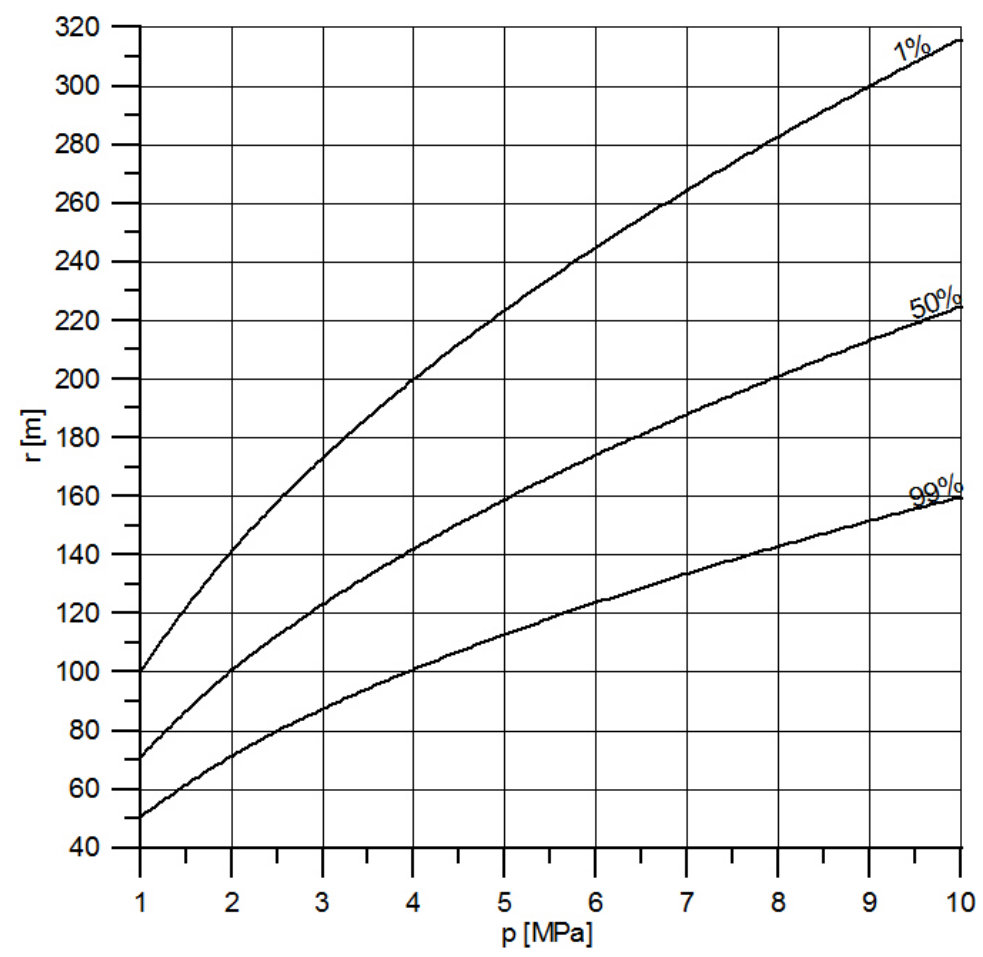

Fig. 9. Dependence of the size of hazardous zones on the gas pressure $(d=0.4 \mathrm{~m}, t=30 \mathrm{~s})$

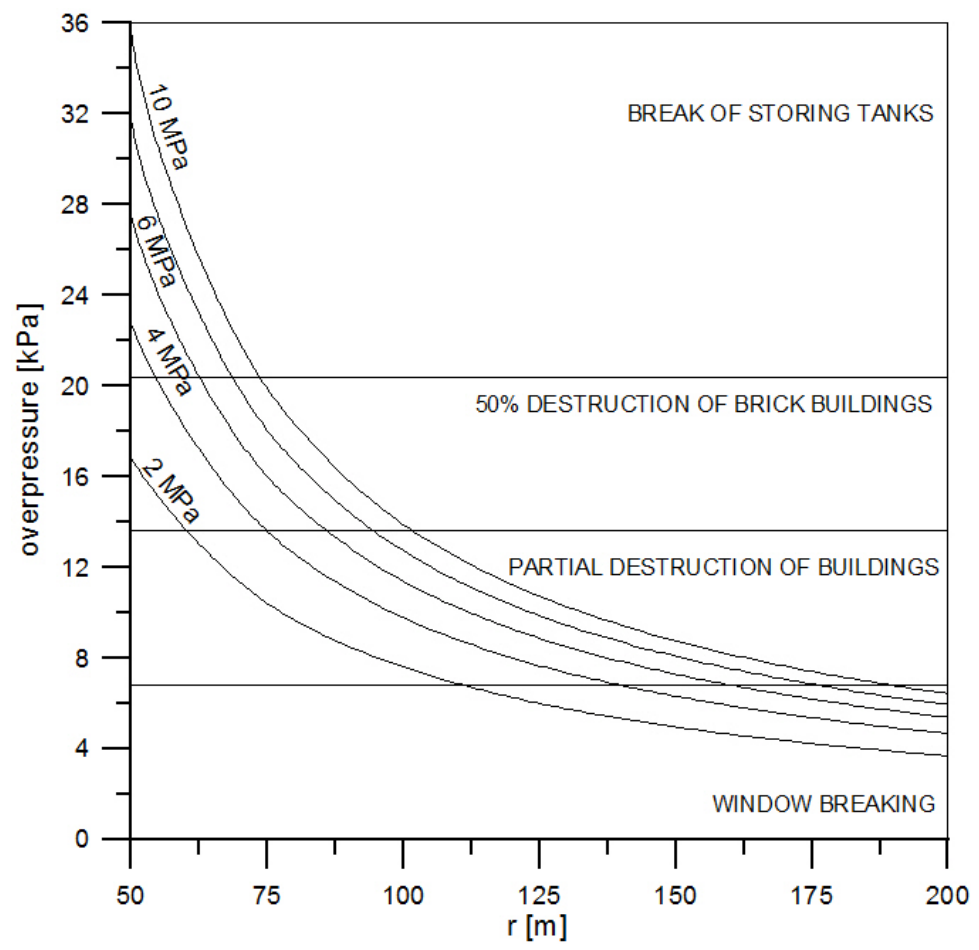

Fig. 10. Dependence of the overpressure arising from the explosion on the distance from the cloud centre $(d=0.05 \mathrm{~m}, t=10 \mathrm{~s})$ 


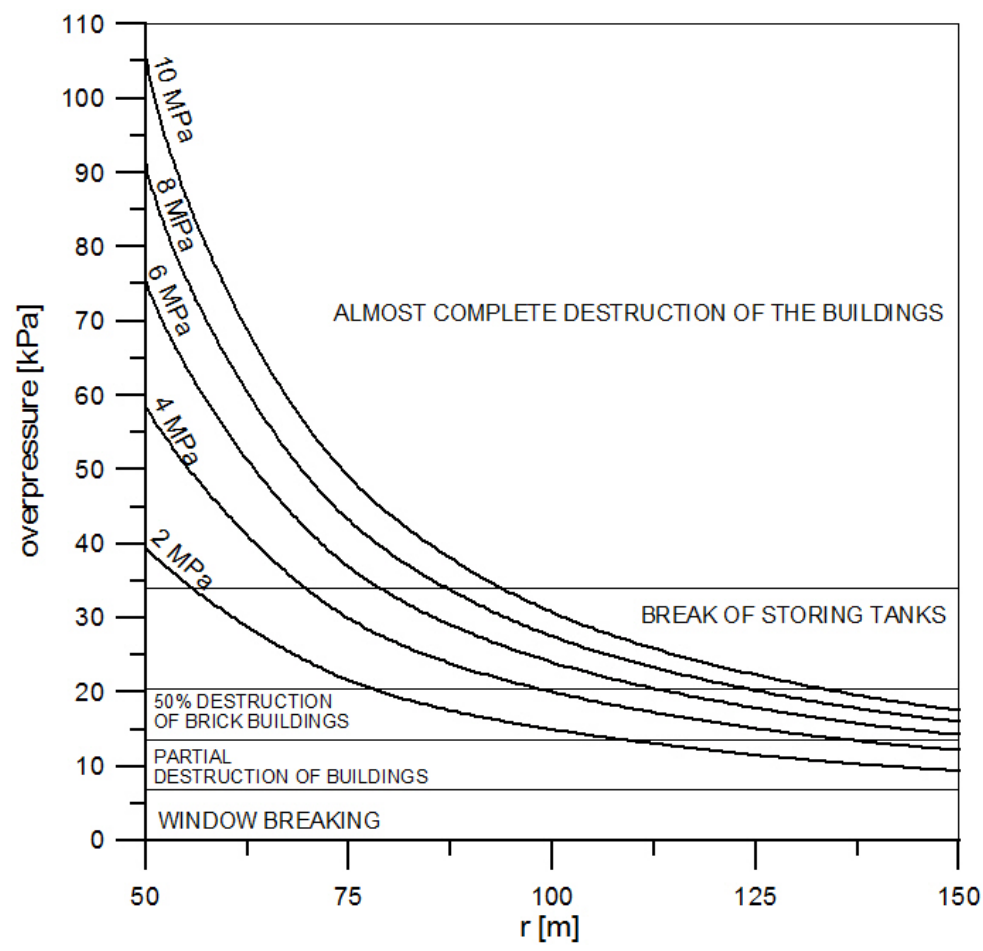

Fig. 11. Dependence of the overpressure arising from the explosion on the distance from the cloud centre $(d=0.05 \mathrm{~m}, t=60 \mathrm{~s})$

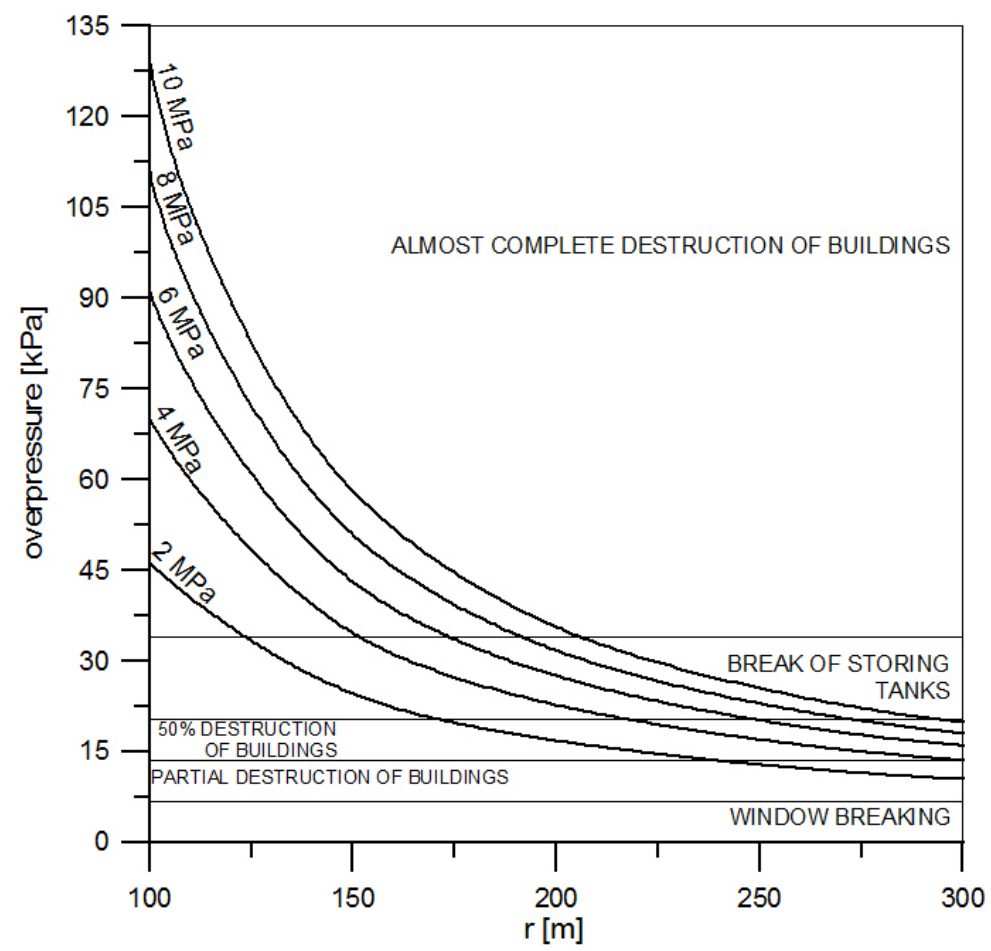

Fig. 12. Dependence of the overpressure arising from the explosion on the distance from the cloud centre $(d=0.4 \mathrm{~m}, t=10 \mathrm{~s})$ 


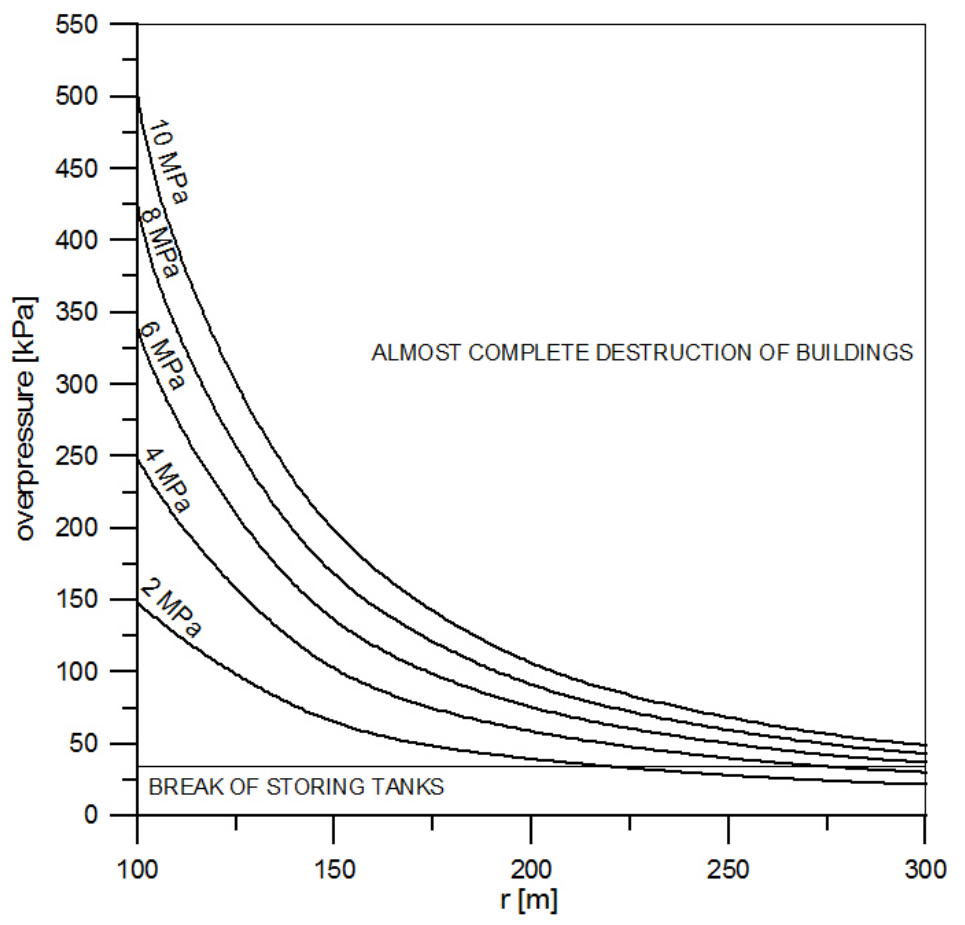

Fig. 13. Dependence of the overpressure arising from the explosion on the distance from the cloud centre

$$
(d=0.4 \mathrm{~m}, t=60 \mathrm{~s})
$$

The range of the zones in which the probability of loss of life is $1 \%, 50 \%$ and $99 \%$ was also analysed. The data are given in Figures 14 and 15 in function of gas pressure in the broken pipeline. They relate to the explosion which occurred 10s after the gas release. The results included in Figures 16 and 17 show the same dependencies, but for an explosion of the hydrogen cloud which was formed in 60 seconds. Both times, i.e. $10 \mathrm{~s}$ and $60 \mathrm{~s}-$ as experience indicates - are the most probable moments for the cloud of released hydrogen to explode.

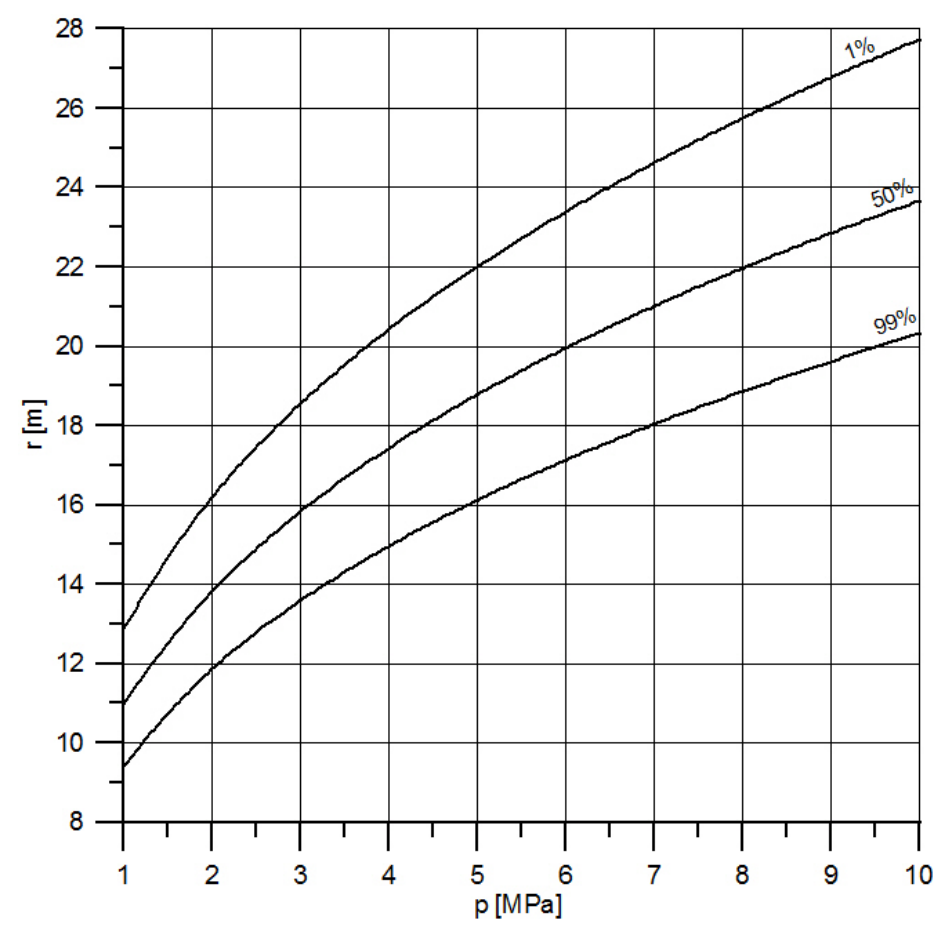

Fig. 14. Dependence of the explosion range on gas pressure $(d=0.05 \mathrm{~m}, t=10 \mathrm{~s})$ 
Modelling the effects of failure of pipelines transporting hydrogen

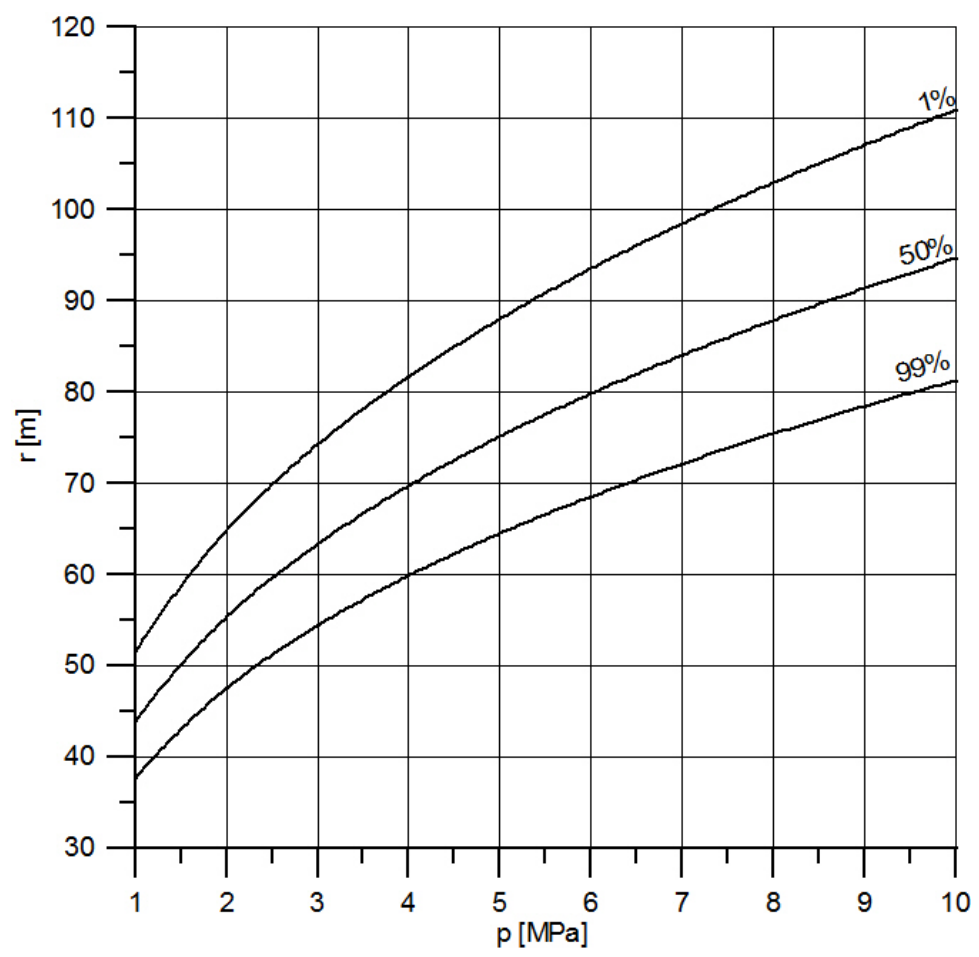

Fig. 15. Dependence of the explosion range on gas pressure $(d=0.4 \mathrm{~m}, t=10 \mathrm{~s})$

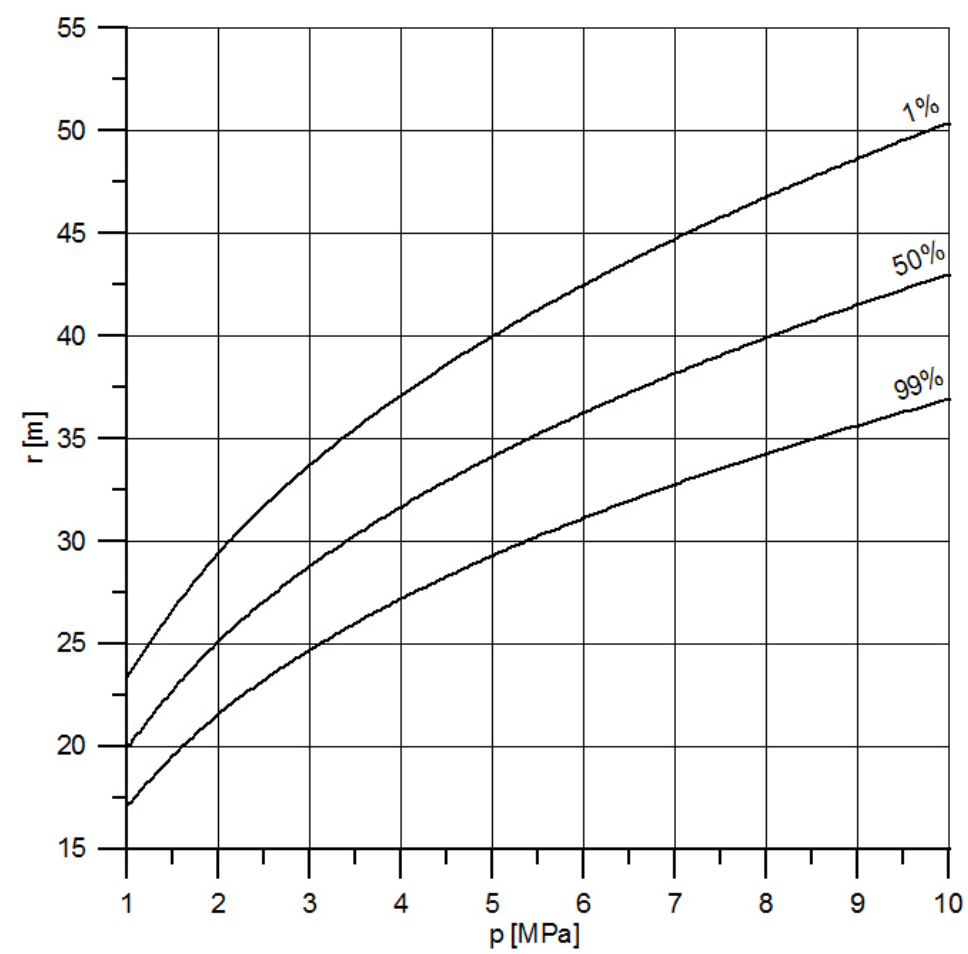

Fig. 16. Dependence of the explosion range on gas pressure $(d=0.05 \mathrm{~m}, t=60 \mathrm{~s})$ 


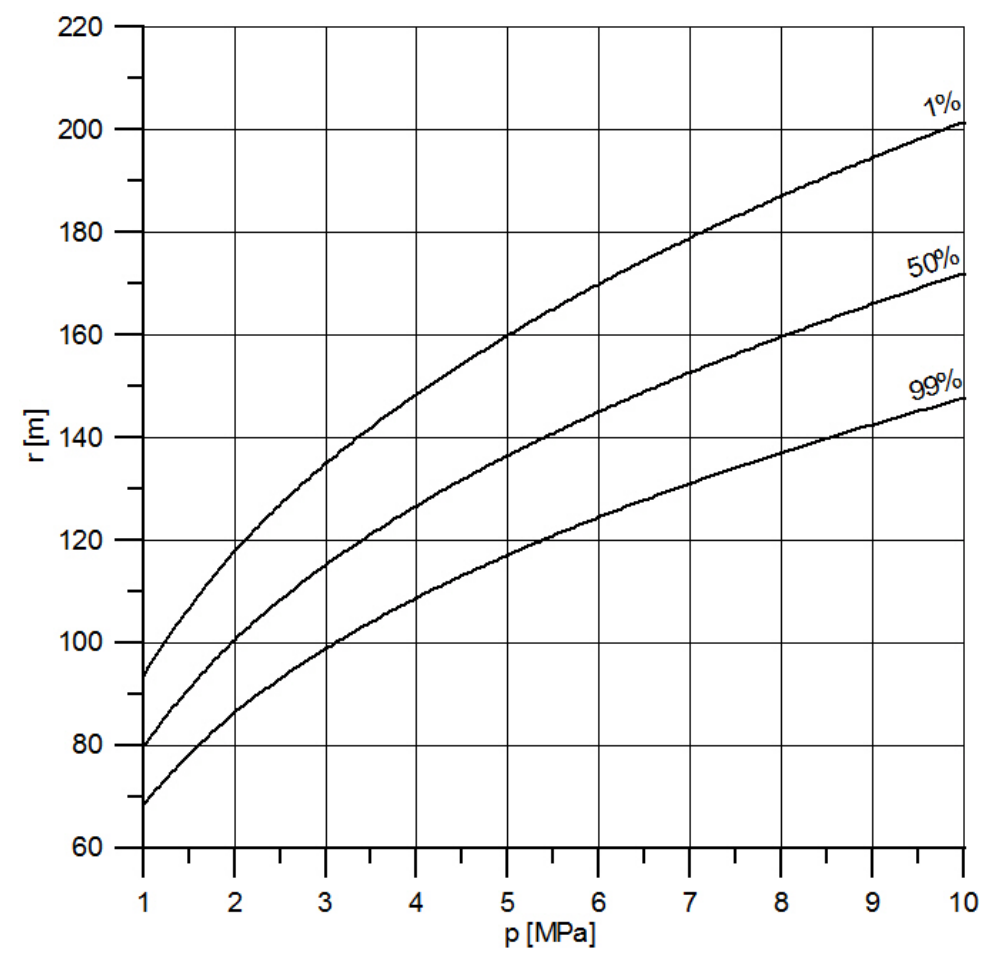

Fig. 17. Dependence of the explosion range on gas pressure ( $d=0.4 \mathrm{~m}, t=60 \mathrm{~s})$

\section{CONCLUSIONS}

Owing to hydrogen properties an uncontrollable leakage and the following ignition of the released hydrogen can lead to dangerous fires or explosions.

The paper presents the results of calculations of the size of hazardous zones surrounding broken pipelines transporting hydrogen. The calculations were made for a hole in the pipeline of an equivalent diameter of $5 \mathrm{~cm}$ and a complete break of pipelines with diameter of $0.4 \mathrm{~m}$. The impact of pressure in the range from 1 to $10 \mathrm{MPa}$ on the amount of mass outflow of hydrogen, and the effects of such outflow were analysed. The effects of the jet fire and of the explosion of a gas cloud formed of released hydrogen were considered in detail. The range of critical zones in which a damage or destruction of facilities, buildings or other infrastructure components would occur was determined. The size of the zones with a probability of life loss resulting from heat radiation or the pressure wave was estimated using probit functions. At minor breaks of a high-pressure pipeline (hole diameter of $5 \mathrm{~cm}$ ) from which a jet fire can result, the zone in which the probability of life loss under a 15 -second exposure exceeds $50 \%$ takes up an area within the radius of approx. $22 \mathrm{~m}$. At a complete break of a pipeline with a diameter of $0.4 \mathrm{~m}$ under a 15 -second exposure to the arising radiation, the area in which life loss probability is $50 \%$ has a radius of $175 \mathrm{~m}$. Under longer exposure to heat radiation, the example values of the radii of hazardous zones which were given above increase to $27 \mathrm{~m}$ and $225 \mathrm{~m}$, respectively. If the effect of an uncontrollable gas leakage from the $0.4 \mathrm{~m}$ pipeline is a detonation of the formed hydrogen cloud, the hazardous area radius is from $100 \mathrm{~m}$ to $170 \mathrm{~m}$, depending on the time needed for the cloud to form. Therefore, it can be assumed that the radii of areas exposed to the adverse effect of radiation and overpressure are of the same order.

The results presented in this paper were obtained in research work co-financed by the Polish National Centre for Research and Development within the framework of Contract SP/E/1/ 67484/10 - Strategic Research Programme - Advanced technologies for obtaining energy: Development of a technology for highly efficient zero-emission coal-fired power units integrated with $\mathrm{CO}_{2}$ capture. 


\section{SYMBOLS}

A surface area of the flame, $\mathrm{m}^{2}$

$a, a_{s}, a_{l} \quad$ empirical constants

$b, b_{s}, b_{l} \quad$ empirical constants

$d \quad$ diameter of the hole, $\mathrm{m}$

$F \quad$ view factor, -

$H_{c} \quad$ heat of combustion, $\mathrm{J} / \mathrm{kg}$

$L_{f} \quad$ flame length, $\mathrm{m}$

$\dot{m}_{e} \quad$ effective mass flow rate, $\mathrm{kg} / \mathrm{s}$

$\dot{m}_{\max } \quad$ maximum mass flow rate, $\mathrm{kg} / \mathrm{s}$

$p \quad$ pressure, $\mathrm{Pa}$

$P_{r} \quad$ probit function, -

$q$ radiational heat flux, $\mathrm{W} / \mathrm{m}^{2}$

$Q_{s} \quad$ combustion energy per unit time, $\mathrm{J} / \mathrm{s}$

$r \quad$ radius, $\mathrm{m}$

$t \quad$ time, $\mathrm{s}$

$W_{f} \quad$ flame width, $\mathrm{m}$

$\Delta p \quad$ explosion overpressure, $\mathrm{kPa}$

Greek symbols

$\eta \quad$ ratio of total heat radiated to total heat released from fire, -

$\kappa \quad$ specific heat ratio, -

$\rho \quad$ density, $\mathrm{kg} / \mathrm{m}^{3}$

$\tau_{a} \quad$ atmospheric transmissivity, -

\section{REFERENCES}

Buczek B., Czepirski L., Ziętkiewicz J., 2007. Optimization of hydrogen volumetric storage capacity for microporous carbon materials, Chem. Process Eng., 28, 47-55.

EC Regulation, 2009. Regulation (EC) No 79/2009 of the European Parliament and of the Council of 14 January 2009 on type-approval of hydrogen-powered motor vehicles, and amending Directive 2007/46/EC, available at: http://eur-lex.europa.eu/LexUriServ/LexUriServ.do?uri=CELEX:32009R0079:en:NOT

Elvers B., 2008. Handbook of fuels. Viley-VCH, Wienhaim.

Gerboni R., Salvador E., 2009. Hydrogen transportation systems: Elements of risk analysis. Energy, 34, 22232229. DOI: $10.1016 /$ j.energy.2008.12.018.

Guidelines for evaluating the characteristics of vapour cloud explosions, flash fires and BLEVES, 1998. American Institute of Chemical Engineers, New York.

Houf W., Schefer R., 2007. Predicting radiative heat fluxes and flammability envelopes from unintended releases of hydrogen. Int. J. Hydrogen Energy, 32, 136-151. DOI: 10.1016/j.ijhydene.2006.04.009.

Lachance J., Tchouvelev A., Engebo A., 2011. Development of uniform harm criteria for use in guantitative risk analisys of hydrogen infrastructure. Int. J. Hydrogen Energy, 36, 2381-2388. DOI: 10.1016/j.ijhydene.2010.03.139.

Lobato J., Cańizares P., Rodrigo M.A., Sáez C., Linares J.J., 2006. A comparison of hydrogen cloud explosion models and the study of the vulnerability of the damage caused by an explosion of $\mathrm{H} 2$. Int. J. Hydrogen Energy, 31, 1780-1790. DOI: 10.1016/j.ijhydene.2006.01.006

Mogi T., Horiguchi S., 2009. Experimental study on the hazards of high-pressure hydrogen jet diffusion flames. $J$. Loss Prev. Process Ind., 22, 45-51. DOI: 10.1016/j.jlp.2008.08.006.

Rigas F., Sklavounos S., 2005. Evaluation of hazard associated with hydrogen storage facilities. Int. J. Hydrogen Energy, 30, 1501-1510. DOI: 10.1016/j.ijhydene.2005.06.004. 
Scheffef R.W., Houf W.G., Williams T.C., Bourne B., Colton J., 2007. Characterization of high-pressure, underexpanded hydrogen-jet flames. Int. J. Hydrogen Energy, 32, 2081-2093. DOI: 10.1016/j.ijhydene.2006.08.037.

Surygała J., 2008. Hydrogen as fuel. WNT, Warszawa (in Polish).

van den Bosch C.J.H., Weterings R.A.P.M. (Eds.), 2005. Methods for the calculation of physical effects. Yellow Book. The Hague.

Yo Y.-D., Ahn B.J., 2006. Analysis of hazard area associated with hydrogen gas transmission pipelines. Int. J. Hydrogen Energy, 31, 2122-2130. DOI: 10.1016/j.ijhydene.2006.01.008. 